\title{
Use of Gases in Pyrometallurgy
}

\author{
DEAN GREGUREK, ${ }^{1,5}$ ZHIWEI PENG,${ }^{2,6}$ CHRISTINE WENZL, 3 \\ and JESSE F. WHITE ${ }^{4,8}$ \\ 1.-Technology Center Leoben, RHI AG, 8700 Leoben, Austria. 2.-School of Minerals Processing and \\ Bioengineering, Central South University, Changsha 410083, Hunan, People's Republic of China. \\ 3.-RHI AG, 1100 Vienna, Austria. 4.-Elkem Carbon AS, NO-4675, Kristiansand, Norway. 5. - e-mail: \\ dean.gregurek@rhi-ag.com. 6.-e-mail: zwpeng@csu.edu.cn. 7.-e-mail: christine.wenzl@rhi-ag.com. \\ 8.—e-mail: jesse.white@elkem.no
}

Gases play an important role in pyrometallurgical processes and are found in different applications: reactive gases that are involved in the actual chemical reactions, inert gases that improve bath agitation or melt degassing, gases for burner operation that provide heat or adjust the process atmosphere, and oxygen lancing that is involved in taphole opening. When considering gas injection, it is possible to introduce the gas from the top, side, or bottom; thus, various technologies have been developed with lance, tuyere, and plug systems in vertical and horizontal vessels, and they are the subject of ongoing research and improvements. A breakthrough in gas use was the invention of the LD process (LD for Linz-Donawitz, the two Austrian cities where the process was invented) in steel metallurgy in 1948 and its subsequent applications in steel production in the $1950 \mathrm{~s}$, replacing the Bessemer process. Similar processes are also used in ferroalloy production. Already in 1908 the Peirce Smith converter for copper converting, which is still the prevailing converting technology today, had been invented, based on the Bessemer process but carried out in a horizontal vessel. Generally, gases are important in all nonferrous metal production stages today, namely, roasting, smelting, converting, and refining. One ongoing trend is the use of oxygen-enriched air leading to higher intensity processes, which also require subsequent adaptations in other furnace equipment, e.g., coolers and refractories.

The articles in this topic provide some updates on research and applications of gas use in pyrometallurgy. They also mark the end of Dean Gregurek's activity as editor, which will end with this current

Dean Gregurek, Zhiwei Peng, and Jesse White are the JOM advisors for the Pyrometallurgy Committee of the TMS Extraction \& Processing Division, and guest editors for the topic Use of Gases in Pyrometallurgy in this issue.
$J O M$ issue. Therefore, these articles are accompanied by a cordial goodbye, hoping you enjoyed the selection of $J O M$ pyrometallurgy issues in the last 3 years and found some interesting and useful information in the selected articles.

The topic starts with a comprehensive study of submerged gas injection by Joel Kapusta. Various submerged gas injection technologies and vessel types are used in nonferrous production today, and some of them have been applied for several decades. The article "Submerged Gas Jet Penetration: A Study of Bubbling Versus Jetting and Side Versus Bottom Blowing in Copper Bath Smelting" provides an excellent overview of submerged gas injection, comprising historical development of the theory and mathematical characterization of gas jet trajectory and penetration, as well as a quantitative comparison of different injection positions (side versus bottom blowing) and the concept, application, and benefits of sonic injection in jetting regime versus standard bubbling regime.

The second article "Mass Transfer Model for the De-Oxidation of Molten Copper" by Gabriel Plascencia et al., is also based on copper production, in this case, the kinetics of deoxidation after the oxidation stage in firerefining. Such deoxidation using reactive (reducing) gas for reduction is common in copper metallurgy, and the present work provides a simple mass transfer model for this process. The model comprises the two subsequent transfer mechanisms for two consecutive stages of the reduction process, namely, transport of the reducing gas from the bubble toward the melt-gas interface and oxygen transfer from the melt bulk toward the gas-melt interface, respectively. The model accounts for gas fluid flow and other process parameters such as lance submergence and nozzle diameter.

The next three articles deal with novel gaseous reduction agents, namely, the use of ethanol for $\mathrm{NiO}$ reduction, use of undiluted methane for $\mathrm{Fe}_{2} \mathrm{O}_{3}$ reduction, and pyrolysis gas for $\mathrm{Pb}-\mathrm{Zn}$ residues. 
The article "Reduction of Nickel Oxide with Ethanol" by Senol Cetinkaya et al. investigates the reduction behavior of $\mathrm{NiO}$ powder by ethanol vapor. The authors demonstrated that $\mathrm{NiO}$ could be completely reduced to $\mathrm{Ni}$ by ethanol as predicted by the thermodynamic analysis. They also confirmed the suitability of undiluted methane for a single-step solid-state reduction of $\mathrm{Fe}_{2} \mathrm{O}_{3}$, namely sponge iron production. The findings are described in the article "A Single-Step Process for Direct Reduction of Iron Oxide to Sponge Iron by Undiluted Methane."

As sustainability, "zero waste" and $\mathrm{CO}_{2}$ footprint are important issues in the generally emissionintense pyrometallurgical industry, the use of a renewable reducing agent for the recycling of zincand lead-bearing residues was studied and described in the article "Pyrolysis Gas as Renewable Reducing Agent for the Recycling of Zinc- and LeadBearing Residues: A Status Report" by Christoph Pichler and Jürgen Antrekowitsch. It describes a promising process for treating Waelz slag in a vertical retort with a pyrolysis gas from metallurgical charcoal production, which is based on biomass or wood containing huge quantities of combustible components. The contained zinc is reduced and subsequently evaporated in the vertical column and afterward reoxidized outside the retort. Also, lead or some lead compounds follow the zinc into the gas phase. The generated metallic iron remains in the solid material.

The next article "A Gas Purging System for Copper and Aluminium Furnaces" by Goran Vukovic and Klaus Gamweger provides an overview of gas purging technologies applied in copper and aluminum production. The article describes the use of inert and reactive gases in different metallurgical vessels. Furthermore, the results of industrial applications are presented, showing the benefits of gas purging.
The top submerged lancing (TSL) technology has been used for several decades for various metals. The last article in this topic, "Energy Efficiency of the Outotec Ausmelt TSL Process for Primary Copper Smelting" by Jacob Wood et al., provides an overview of the TSL technology, as well as an update on recent advances. Different copper production flow sheets including TSL technology are compared. A noteworthy feature of the work is the comparison between TSL and the recently developed Chinese bottom blown smelting (BBS) process.

The following articles are published under the topic "Use of Gases in Pyrometallurgy" in the June 2017 issue (vol. 69, no. 6) of JOM and can be accessed via the JOM page at http://link.springer. com/journal/11837/69/6/page/1link.springer.com:

- "Submerged Gas Jet Penetration: A Study of Bubbling Versus Jetting and Side Versus Bottom Blowing in Copper Bath Smelting" by Joël Kapusta.

- "Mass Transfer Model for the De-Oxidation of Molten Copper" by Lamberto Díaz-Damacillo, Fidel Reyes, Alberto Ingalls, Claudio Méndez, and Gabriel Plascencia.

- "Reduction of Nickel Oxide with Ethanol" by F. Coskun, S. Cetinkaya, and S. Eroglu.

- "A Single-Step Process for Direct Reduction of Iron Oxide to Sponge Iron by Undiluted Methane" by S. Cetinkaya and S. Eroglu.

- "Pyrolysis Gas as Renewable Reducing Agent for the Recycling of Zinc- and Lead-Bearing Residues: A Status Report" by C. Pichler and J. Antrekowitsch.

- "A Gas Purging System for Copper and Aluminum Furnaces" by Goran Vukovic and Klaus Gamweger.

- "Energy Efficiency of the Outotec Ausmelt TSL Process for Primary Copper Smelting" by Jacob Wood, Joey Hoang, and Stephen Hughes. 